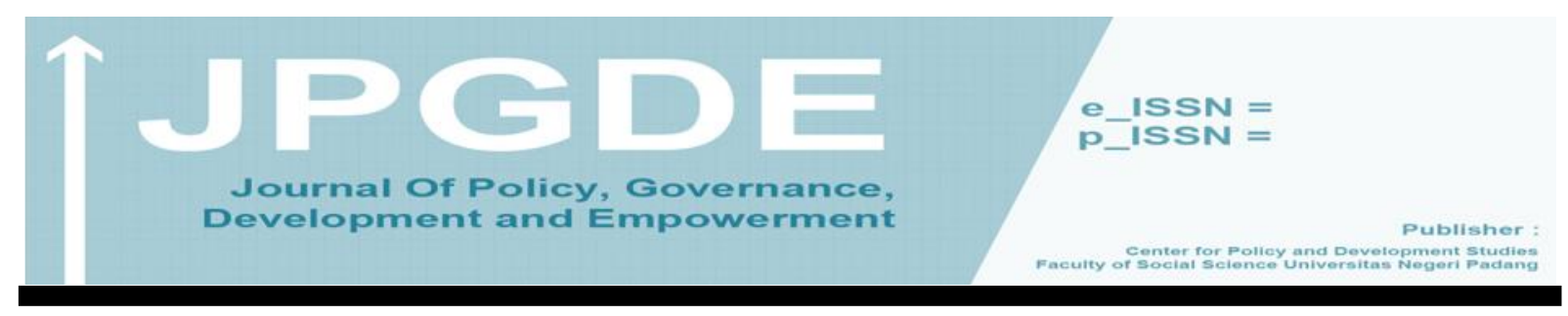

\title{
EFEKTIVITAS KAPASITAS KELEMBAGAAN BADAN PENENANGGULANGAN BENCANA DAERAH (BPBD) PROVINSI SUMATERA BARAT DALAM MENGURANGI RISIKO BENCANA
}

\author{
Ade Lestari , Zikri Alhadi
}

\begin{abstract}
This researxh describes the effectiveness of the institutional capacity of the West Sumatra Province BPBD in reducing disaster risk with all forms of effort and coordination. The purpose of this study was to determine the effectiveness of the institutional capacity of West Sumatra Province BPBD in an effort to reduce disaster risk. This research method is a qualitative method. The locations of the study were scattered at the West Sumatra Province BPBD office, informant's residence and via telephone. Data collection uses interviews, observation, and study documentation. The research informants were several heads of departments, section heads and staff at the West Sumatra Province Regional Development Planning Agency and several members of the forum and non-governmental disaster risk reduction organizations. The results of the research found are case examples, supporting and inhibiting factors, from which conclusions can be drawn on how effective the BPBD of West Sumatra Province is in reducing disaster risk.
\end{abstract}

Keywords: Effectiveness, Institution, Disaster

\begin{abstract}
Abstrak
Penelitian ini mendeskpsikan tentang efektivitas kapasitas kelembagaan $B P B D$ Provinsi Sumatera Barat dalam mengurangi risiko bencana dengan segala bentuk upaya dan koordinasi. Tujuan penelitian ini untuk Mengetahui efektivitas kapasitas kelembagaan BPBD Provinsi Sumatera Barat dalam upaya mengurangi risiko bencana. Metode penelitian ini adalah metode kualitatif. Lokasi penelitian tersebar yaitu dikantor BPBD Provinsi Sumatera Barat, kediaman informan dan via telepon. Pengumpulan data menggunakan cara wawancara, observasi, dan studi dokumentasi. Informan penelitiannya adalah beberapa kepala bidang, kepala seksi dan staf diBPBD Provinsi Sumatera Barat serta beberapa anggota forum dan non governmental organization pengurangan risiko bencana. Hasil penelitian yang ditemukan yaitu contoh kasus, faktor pendukung dan penghambat, dari situlah dapat diambil kesimpulan mengenai seberapa efektifkah BPBD Provinsi Sumatera Barat dalam mengurangi risiko bencana.
\end{abstract}




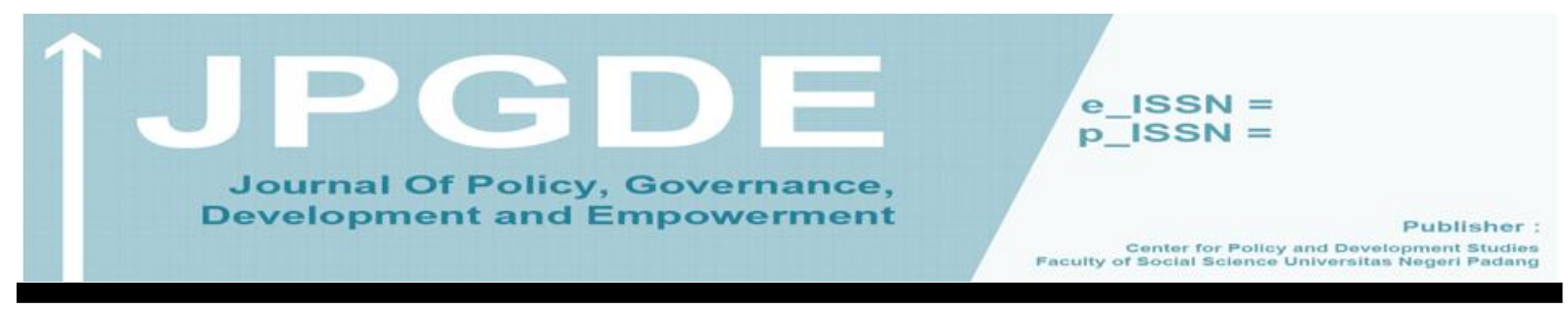

Kata Kunci : Efektivitas, Lembaga, bencana.

\section{Pendahuluan}

Bencana merupakan kejadian yang mengerikan bagi umat manusia, baik itu bencana alam maupun bencana sosial yang penyebabnya ulah tangan manusia. Bencana pun sangat kecil kemungkinan akan kita hindari apabila kita kurang persiapan dan pengetahuan mengenai kebencanaan.

Dalam Undang - Undang Nomor 24 tahun 2007 tentang Penanggulangan Bencana, bencana adalah peristiwa atau rangkaian peristiwa yang mengancam dan mengganggu kehidupan dan penghidupan masyarakat yang disebabkan, baik oleh faktor alam dan/atau faktor nonalam maupun faktor manusia sehingga mengakibatkan timbulnya korban jiwa manusia, kerusakan lingkungan, kerugian harta benda, dan dampak psikologis.

Perihal kebencanaan pada masa dewasa ini umat manusia sudah mulai berfikir bagaimana cara agar meminimalisir terjadinya bencana atau minimal mengurangi dampak daripada bencana. Dengan mengupayakan berbagai cara termasuk dengan mengorganisir massa agar dapat menjadi manusia - manusia yang waspada dan siaga dalam menghadapi keterkejutan akan bencana.

Indonesia sebagai negara yang rawan akan terjadinya bencana turut serta dalam upaya penanggulangan dan mitigasi bencana. Salah satu upayanya adalah membentuk perangkat khusus untuk memanajemen akan kebutuhan terhadap upaya dalam penanggulangan, pengurangan, mitigasi bencana dan sebagainya. Provinsi Sumatera Barat yang juga secara geografis memiliki banyak potensi bencana tentu membutuhkan suatu sistem dan upaya agar segala risiko dan kerusakan bisa diminimalisir.

BPBD Provinsi Sumatera Barat hadir daam bentuk upaya pemerintah dalam menjawab tantangan kebencanaan diprovinsi Sumatera Barat khususnya. Segala bentuk upaya yang dimaksud tentu harus jelas sistematika dan penanggung jawabnya, maka kelembagaan dalam BPBD Provinsi Sumatera Barat sendiri harus memiliki kapasitas yang cukup, baik dari segi personil, skill personil maupun logistitik.

Penelitian ini membahas mengenai kapasitas kelembagaan tersebut. Kapasitas kelembagaan pada BPBD Provinsi Sumatera Barat sangat penting untuk ditinjau sebagai tolak ukur efektifnya setiap kinerja mereka dalam program - program penanggulangan bencana diprovinsi Sumatera Barat.

Adapun dalam setiap program yang dijalani adanya ditemukan beberapa faktor pendukung dan penghambat yang bisa mempengaruhi keberhasilan program - program kerja dari BPBD Provinsi Sumatera Barat. Sedangkan setiap keberhasilan program juga dapat diambil penilaian mengenai efektivitas kapasitas kelembagaan BPBD Provinsi Sumatera Barat.

Berdasarkan pendahuluan diatas maka terdapat tinjauan pustaka yang relevan terhadap penelitian ini yaitu sebagai berikut: 
A. Pengertian Efektivitas

Menurut Steers (1977) dalam Edy Sutrisno (2011:123-124), efektivitas dikaitkan dengan tujuan organisasi, yaitu laba yang cenderung mengabaikan aspek terpenting dari keseluruhan prosesnya, yaitu sumber daya manusia.

B. Pengertian Kapasitas Kelembagaan

Kapasitas Menurut Kapucu, Healy, dan Arslan (2011) dalam Gita dan Maya (Volume 4 No. 1 (76-86). 2016:77) Adalah suatu sumberdaya, tingkat kepemimpinan, kemampuan atau keahlian masyarakat yang memadai, tingkatan tertentu pada pelembagaan (perubahan hal-hal baru yang bernilai baik)

C. Pengertian Lembaga

Djogo, Sunaryo, dan Sirait (2003) dalam Gita dan Maya (Volume 4 No. 1 (76-86). 2016:77) menyebutkan bahwa umumnya definisi lembaga mencakup konsep pola perilaku sosial yang sudah mengakar dan berlangsung terus menerus atau berulang.

D. Pengertian Integrasi

Integrasi sendiri dapat diartikan sebagai proses penyesuaian antara unsur-unsur yang saling berbeda dalam kehidupan masyarat sehingga dapat menghasilkan pola kehidupan yang lebih serasi. Integrasi ini tentu saja sangat diperlukan karena hal ini merupakan kekuatan penting bagi masyarakat dalam menghadapi permasalahan-permasalahan terkait dengan menangani bencana alam (Agus dan Arqom. 2012: 99).

E. Pengertian Koordinasi

Inti dari koordinasi adalah proses pengelolaan ketergantungan antar aktivitas; yang terdapat dalam organisasi (human system), ketergantungan aktivitas juga berarti ketergantungan antar pelaku atau aktor yang menjalankannya. Koordinasi merupakan inti dari operasi organisasi, yang memungkinkan tujuan-tujuan yang ingin dicapai organisasi dapat diraih (Nia. 2012:76).

\section{F. Pengertian Manajemen Bencana}

Khan menjelaskan dalam Zikri (Vol. XIII No.1 Th. 2014 ) secara komprehensif defenisi dari manajemen bencana sebagai "sum total of all activities, programmes and measures which can be taken up before, during and after a disaster with the purpose to avoid a disaster, reduce its impact or recover from its losses."(Khan; 46) Untuk mencari solusi atas persoalan bencana yang merupakan masalah publik, maka dibutuhkan manajemen bencana agar dampak buruk dari bencana bisa direduksi.

G. Pengertian Manajemen Risiko 


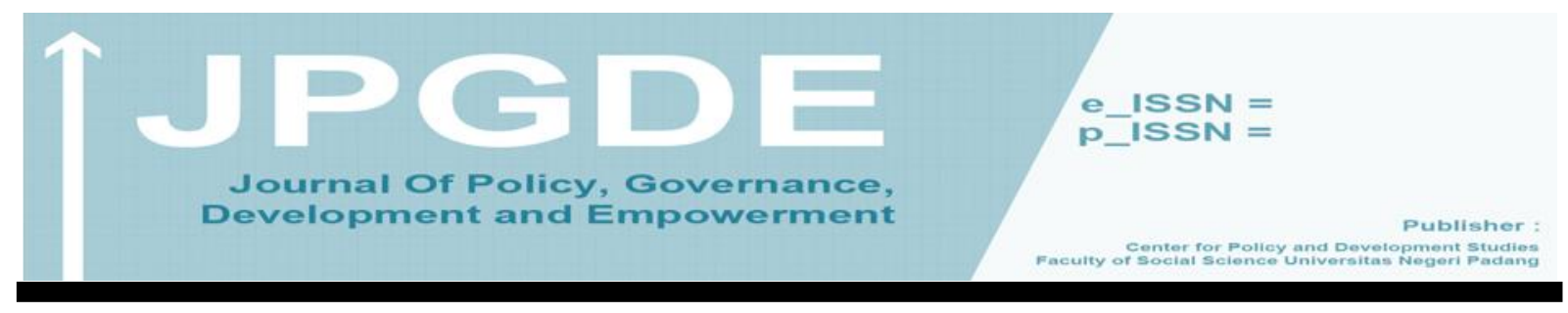

Manajemen risiko adalah seperangkat kebijakan, prosedur yang lengkap, yang dipunyai organisasi, untuk mengelola, memonitor dan mengendalikan eksposur organisasi terhadap risiko" (Hanafi, 2006: 26)

\section{Metode Penelitian}

Penelitian ini menggunakan metode kualitatif, Jenis kualitatif yang diambil dalam penelitian yang dilakukan adalah penelitian deskriptif. Penelitian deskriptif yaitu penelitian yang dimaksudkan untuk membuat pengindraan (gambaran) gambaran mengenai situasi-situasi atau kejadian-kejadian (Sumadi. 2013, 76). Pengambilan data dalam penelitian ini menggunakan teknik wawancara, observasi dan studi dokumentasi. Lokasi penelitian dalam penelitian ini antra lain dikantor BPBD Provinsi Sumatera Barat, terletak di jalan Jenderal Sudirman, Nomor 47, Kelurahan Padang Pasir, Kecamatan Padang Barat, Kota Padang; Kediaman informan, bapak Khalid Syaifullah di Lubuk Lintah, Kuranji, Kota Padang; Via telepon

\section{Hasil dan Pembahasan}

Berbicara mengenai efektivitas kapasitas kelembagaan BPBD Provinsi Sumatera Barat diketahui bahwa belum ada ukuran pasti. Sebagai ukuran efektivitas adalah kompetensi wawasan, dimana kompetensi wawasan ini merupakan penilaian kinerja terhadap pegawai. Kompetensi wawasan juga sebagai landasan dalam promosi jabatan bagi pegawai.

Evaluasi memang ada namun lebih berguna untuk merancang program program dimasa mendatang yang dinamakan rencana penanggulangan bencana (RPB), RPB ini untuk 5 tahun kedepan, karena disini termuat rencana rencana penanganan bencana termasuk anggaran dan personil yang harus disediakan itulah yang nantinya akan menjadi tolak ukur efektif atau tidaknya program program.

Jika mengacu kepada indikator efektivitas oleh Steer (1977) dalam Edy Sutrisno (2011:123-124) yaitu pengembangan organisasi dalam penilaian efektivitas atau tidaknya kelembagaan BPBD Provinsi Sumatera Barat. Terdapatlah bukti dokumentasi beberapa bentuk realisasi upaya pengembangan kapasitas seperti diadakannya sosialisasi nagari tangguh bencana atau pelatihan tim reaksi cepat. Adapun dalam kegiatan tersebut tentunya secara tak langsung akan didapat manfaat seperti meningkatnya jaringan komunikasi dan koordinasi dalam upaya penanggulangan bencana. Kemudian adanya bentuk forum koordinasi yang memiliki surat keputusan resmi dari pemerintah provinsi Sumatera Barat yaitu Forum PRB tentunya menjadi contoh real dalam pengembangan secara kapasitas kelembagaan oleh BPBD Provinsi Sumatera Barat, sedangkan anggota dari Forum PRB sendiri berasal dari perwakilan badan pemerintahan setingkat, lebih tinggi maupun badan non pemerintah.

Jika mengacu kepada teori produksi BPBD Provinsi Sumatera Baratpun 


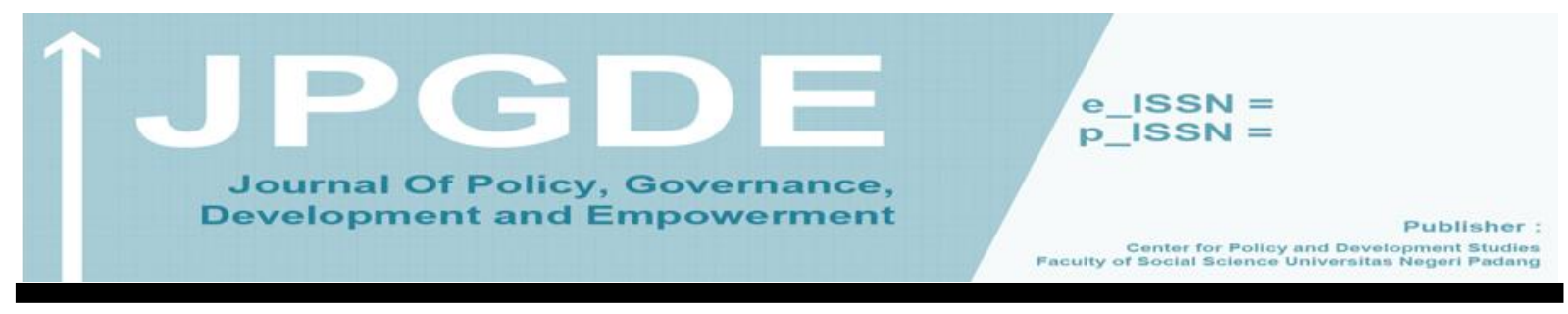

memeiliki kriteria tersebut. Contoh kecil dari BPBD Provinsi Sumatera Barat dalam hal produksi yaitu mengadakan SPAB yang sasarannya adalah lembaga pendidikan tingkat menengah atas yang bertujuan untuk sosialisasi tanggap bencana. Program SPAB tersebut diharapkan dapat menciptakan manusia yang tangguh bencana.

Diketahui dari keterangan diatas berarti penilaian - penilaian kinerja tentu memang ada untuk sebagai bahan pertimbangan pembuatan program. Terlihat dari informasi yang bahwa terkait efektivitas BPBD Provinsi Sumatera Barat dapat dilihat secara program yang terjalani.

Selain itu yang menjadi ukuran dalam efektivitas BPBD Provinsi Sumatera Barat adalah faktor pendukung dan penghambatnya itu sendiri. Dari hasil wawancara yang telah dilakukan pada umumnya lebih banyak ditemukan faktor pendukung dan permasalahan yang tak begitu memiliki tingkat kesulitan yang berat, sehingga BPBD Provinsi Sumatera Barat dapat menjalankan program program yang telah disusun dan melakukan tanggap bencana.

\section{Kesimpulan}

Cukup efektifnya kapasitas kelembagaan BPBD Provinsi Sumatera Barat. Pada awalnya memang ukuran efektivitas belum dapat ditentukan namun berdasarkan pengamatan dan pertimbangan pada faktor pendukung dan penghambat maka dapat dikatakan efektivitas kapasitas kelembagaan BPBD Provinsi Sunatera Barat dalam mengurangi risiko bencana cukup baik dan efektif.

\section{Daftar Rujukan}

Buku

Ahmadi, Rulam. 2014. Metodologi Penelitian Kualitatif. Yogyakarta:Ar-ruzz Media.

Basrowi dan suwandi. 2008. Memahami penelitian kualitatif. Jakarta: Rineka Cipta.

Moleong, Lexy. 2005. Metodologi Penelitian Kualitatif. Bandung: Remaja Rosdakarya.

Suryabrata, Sumadi. 2013. Metodologi Penelitian. Jakarta : Rajagrafindo Persada. Sutrisno, Edi. 2011. Budaya Organisasi. Jakarta: Kencana.

Agus dan Arqom. 2012. Konstruksi Masyarakat Tangguh Bencana. Yogyakarta: Mizan Pustaka. 


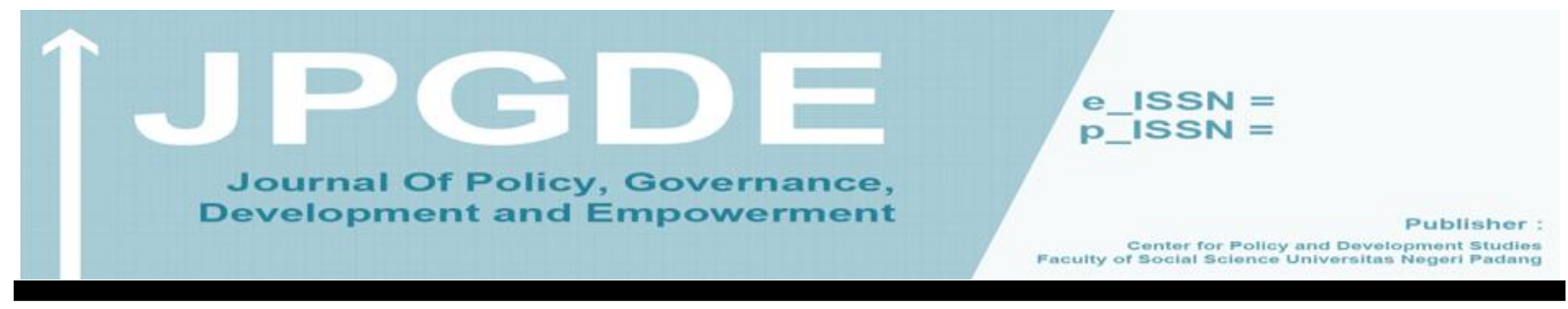

Zikri Alhadi. 2014. "Kesiapan Jalur dan Lokasi Evakuasi Publik Menghadapi Resiko Bencana Gempa Dan Tsunami Di Kota Padang (Studi Manajemen Bencana)". Humanus, Vol. XIII No.1.

Jurnal

Gita Ratri Prafitri dan Maya Damayanti. 2016. “Kapasitas Kelembagaan dalam Pengembangan Desa Wisata (Studi Kasus: Desa Wisata Ketenger, Banyumas)". Jurnal Pengembangan Kota. Volume 4 No. 1 (76-86)

Nia Juliawati. 2012. "Koordinasi dan Usaha Koordinasi dalam Organisasi : Sebuah Kerangka Studi”. Jurnal Administrasi Bisnis, Vol.8, No.2: hal. 177-192 